\title{
Dynamic Characteristics Analysis and Structure Optimization Study of Glaze Spraying Manipulator
}

\author{
Hao Feng, Yong-jun Zhan and Xiao-ping Wang \\ School of Mechanical and Electronic Engineering, Jingdezhen Ceramic Institute, Jiang xi, Jingdezhen, 333403, China
}

\begin{abstract}
A new type of glaze spray manipulator is studied with a three-dimensional entity modal. The dynamic characteristics of its structure have been analysis by finite element method. The first ten other modes of vibration and their natural frequencies were obtained. It is found out that the frequency peak appears at $10 \mathrm{~Hz}$ and the max deformation occurs in sixth order vibration mode by the observation of the end of spray gun on the manipulator. Furthermore, an improvement structure is provided to reinforce the stiffness and the thickness of rotation support at the manipulator's wrist (the end joint). By test verification, it is proved that the max deformation is reduced after structure improvements.
\end{abstract}

\section{Introduction}

The technology of spraying manipulator was developed in the early 1990s and widely adopted in the auto industry [1] etc. There are many advantages such as reducing labour intensity, making the spraying process constant, improving spraying efficiency and so on. It was quite obvious in the production with a little change of the size. For many varieties and small quantity production, a new type manipulator was designed whose structure is a suspension type with a movable base [2]. For eliminating the bob-weight, a linkage mechanism was applied to the movement of the third arm [3]. As a result, the nature frequency is reduced with the weight saving. The precision should be decreased in high-speed status too. So it is necessary to analysis its dynamic characteristics and study the optimum its structure for improving the accuracy of its end movement.

\section{Pre-processing Finite Element Model (FEM)}

\subsection{Three-dimensional model simplification}

The glaze spraying manipulator is composed of base, pillar, roof spport rotation mechanism, arm rotation mechanism, wrist rotation mechanism, spray gun etc.The structure of the study is huge and complex, thus it is necessary to simplify the model.According to Sain Vaint Principle, the model is simplified by deletingfillets, chamfers, undercuts, threaded holes and other small structures while improving the uniformity of mesh distribution[4]. Then the calculation efficiency and accuracy will utmost improved. The three-dimensional model is shown in Fig. 1.

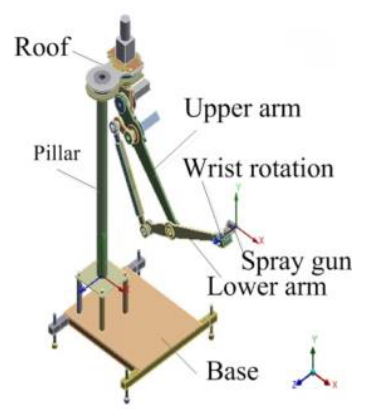

Figure 1. The three-dimensional model and coordinate system.

A movement interference check of moving parts for the model is processed by Solidworks Motion [5] based on the simplified model.The structure space layout interference collision and motion mechanism collision will be found by motion interference checking. If the interference occurred, the exact location will be found out and displayed in the window which is shown in Figure2. Then, the interference parts will be modified accordingly.

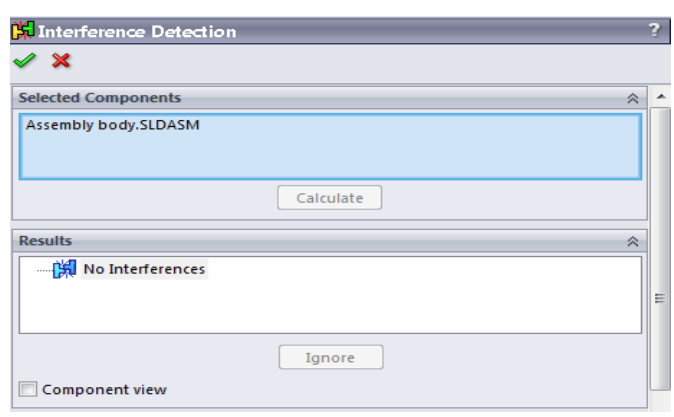

Figure 2. The motion interference prompt window. 
The operating procedure is that selecting the "IntelliMotion Builder" button in drop-down menu and setting motion parameters of each joint in Motion plugin. Click the "Interferences" and " Calculate" button in turn, so that the motion interference checkwill be carried out. In this paper, there is no motion interference of the model after analysis.Therefore, it provides a reasonable and effective model for the subsequent finite element analysis.

Import the model into ANSYS Workbench and create a global coordinate system where the circle center is at the center of uprights bottom [6]. The global coordinate systems is shown in Fig. 1. The $\mathrm{X}$ axis is parallel the upper and lower arm plane, the $\mathrm{Y}$ axis is parallel the pillar axis and the $Z$ axis is vertical the upper and lower arm. Building a local coordinate system with the same directions of global coordinate at the end of spraying gun and let the circle center at the center of the plane.

\subsection{Material definition and constraints addition}

In order to reduce the rotational inertia of manipulator, an operation that cutting weight from upper arm to the end of spray gun has launched. Therefore, the upper and lower arm of the manipulator are replaced by aluminum alloy $(\rho=2.77 \times 10-6 \mathrm{~kg} / \mathrm{mm} 3, \mathrm{E}=7.1 \times 1010 \mathrm{~N} / \mathrm{mm} 2, \mathrm{v}=$ 0.33 ) and other parts are steel. According to the actual situation, the constraints of bond are employed to connect rotary joint and the basis with fix support restraints that make it cannot move and rotate in any direction.In harmonic response analysis, $5 \mathrm{~N}$ harmonic force is applied at the end of spray gun in the direction of vertical the plane.

\subsection{Mesh designing and quality controlling}

Table 1. Mesh quality evaluation parameters.

\begin{tabular}{|c|c|c|c|}
\hline NO. & $\begin{array}{l}\text { Evaluation } \\
\text { Parameters }\end{array}$ & $\begin{array}{c}\text { Evaluation Standard } \\
\text { and Value Range }\end{array}$ & $\begin{array}{c}\text { Averages } \\
\text { Value }\end{array}$ \\
\hline 1 & $\begin{array}{l}\text { element } \\
\text { quality }\end{array}$ & $\begin{array}{l}\text { ranges from } 0 \text { to } 1 \text {, } \\
\text { Optimum value is } 1\end{array}$ & 0.8032 \\
\hline 2 & aspect ratio & $\begin{array}{l}\text { Optimum value is } 1 \text {, } \\
\text { Warning value is } 20\end{array}$ & 1.9973 \\
\hline 3 & Jacobian Ratio & $\begin{array}{l}\text { Optimum value is } 1 \text {, } \\
\text { Warning value is } 40\end{array}$ & 1.1799 \\
\hline 4 & warping factor & $\begin{array}{c}\text { Optimum value is } 0 \text {, } \\
\text { Shell unit limit is } 1 \text {, } \\
\text { Three-dimensional } \\
\text { unit limit is } 7\end{array}$ & 3.6752 \\
\hline 5 & $\begin{array}{c}\text { parallel } \\
\text { deviation }\end{array}$ & $\begin{array}{l}\text { Optimum value is } 0 \text {, } \\
\text { Warning value is } 70^{\circ}\end{array}$ & 8.6005 \\
\hline 6 & $\begin{array}{l}\text { maximum } \\
\text { corner angle }\end{array}$ & $\begin{array}{l}\text { Optimum value for a } \\
\text { triangle is } 60^{\circ} \text {, } \\
\text { Optimum value for } \\
\text { Quadrilateral is } 90^{\circ} \text {, } \\
\text { Warning value is } 155^{\circ}\end{array}$ & $100.6^{\circ}$ \\
\hline 7 & skewness & $\begin{array}{l}\text { ranges from } 0 \text { to } 1 \text {, } \\
\text { Optimum value is } 0\end{array}$ & 0.2468 \\
\hline 8 & Orthogonal & $\begin{array}{l}\text { ranges from } 0 \text { to } 1 \text {, } \\
\text { Optimum value is } 1\end{array}$ & 0.8595 \\
\hline
\end{tabular}

Meshing is a major preprocessing step in finite element analysis. The mesh quality will influence the accuracy of calculation result directly and high-quality mesh will make the result more accurate [7]. The method combined with global and local meshing is used to achieve a high quality mesh, thus the model is divided into 352,962 nodes and 66,388 units. The mesh quality evaluation parameter of ANSYS Workbench is shown in Table 1.

The element quality and skewness are the most important parameters to evaluate the mesh quality. Form table 1 , the element quality value is 0.8032 and skewness is 0.2468 . To the best of our knowledge, the mesh quality is excellent when the skewness value less than 0.25. Therefore, the mesh quality achieves a good foundation for the model calculation.

\section{Modal and harmonic response analysis}

A modal analysis is done for the manipulator to obtain the first ten orders natural frequency and vibration mode, which create an optimized condition for gaining a better dynamic characteristic[8]-[9]. A steady-state response is obtained by harmonic response analysis of a certain linear structure that under a harmonic load and then the frequency amplitude response curve is acquired [10].The dynamic characteristic of manipulator is calculated out after modal and harmonic response analysis, and then provided a basis for further research.

\subsection{Theoretical foundations of modal and harmonic response analysis}

According to the classical mechanics theory, the general kinetic equation is shown in formula (1):

$$
M\left\{x^{\prime \prime}\right\}+C\left\{x^{\prime}\right\}+K\{x\}=\{f(t)\}
$$

where $M$ is mass matrix, $C$ is damping matrix, $K$ is stiffness matrix, $\{x\}$ is displacement vector, $\{f(t)\}$ is force vector, $\left\{x^{\prime}\right\}$ is velocity vector and $\left\{x^{\prime \prime}\right\}$ is acceleration vector.

The classical eigenvalue problem is solved with undamped modal analysis and the correspond kinetic equation is shown in formula (2):

$$
M\left\{x^{\prime \prime}\right\}+K\left\{x^{\prime}\right\}=\{0\}
$$

The free vibration mode of the structure is harmonic, so the displacement is a sine function

$$
x=A \sin (\omega t)
$$

Combined formula (3) and formula (2) that the result is shown in formula (4):

$$
\left(K-\omega^{2} M\right)=\{0\}
$$

A classic eigenvalue problem is represented in formula (4), where $\omega_{i}^{2}$ is eigenvalues and $\omega_{i}$ is natural 
circular frequency. In harmonic response analysis, the general kinetic equation of the manipulator is shown in formula (1). However, the right side of the equation is $F(t)=F_{0} \cos (\omega t)$.

\subsection{Simulation results analysis}

According the vibration theory, the lower order modes have a huge impact on vibration, thus the first ten orders modal is calculated [11].The natural frequency and the vibration trend of first ten orders are shown in Table 2 and the parts of modal vibration modes are shown in Fig. 3.

Form Table 2, the deformation mainly concentrated in the parts from upper arm to the end of spray gun and the natural frequency varied from $3.014 \mathrm{~Hz}$ to $35.483 \mathrm{~Hz}$.According to the vibration trend, the vibration part is limited to the local position with the increase of modal. Fig. 3 shows that the maximum deformation position of first nine orders modal is at the end of the spray gun and the tenth order is at wrist. The maximum amplitude in sixth modal is $29.351 \mathrm{~mm}$ while the value of other modals decreased more than $10 \mathrm{~mm}$.According to above-mentioned analysis, the deformation of the rotating support is the main reason for the manipulator shape.

Table 2. The natural frequency and vibration mode.

\begin{tabular}{|c|c|c|}
\hline NO. & $\begin{array}{c}\text { Frequenc } \\
\text { y (Hz) }\end{array}$ & Modal description \\
\hline 1 & 3.014 & $\begin{array}{l}\text { The whole swing back and forth in } \mathrm{Y} \\
\text { direction }\end{array}$ \\
\hline 2 & 3.744 & Whole panning in $\mathrm{X}$ direction \\
\hline 3 & 3.8673 & $\begin{array}{l}\text { Upper and lower arm swing in } \mathrm{X} \\
\text { direction }\end{array}$ \\
\hline 4 & 5.0374 & $\begin{array}{c}\text { upper and lower arm swing in } \mathrm{X} \\
\text { direction and torsion }\end{array}$ \\
\hline 5 & 9.9721 & $\begin{array}{c}\text { Wrist and the spray gun bobbing in } \mathrm{X} \\
\text { direction }\end{array}$ \\
\hline 6 & 11.431 & $\begin{array}{c}\text { Upper and lower arm swing and } \\
\text { torsion }\end{array}$ \\
\hline 7 & 12.752 & $\begin{array}{c}\text { Whole bobbing around the } \mathrm{Z} \text { axis and } \\
\text { The upper and lower } \\
\text { arm swing in } \mathrm{X} \text { direction }\end{array}$ \\
\hline 8 & 25.905 & $\begin{array}{l}\text { Whole torsion around the } \mathrm{Y} \text { axis and } \\
\text { The upper and lower arm swing }\end{array}$ \\
\hline 9 & 29.917 & $\begin{array}{l}\text { Whole torsion around the } \mathrm{Y} \text { axis and } \\
\text { lower arm and wrist swing }\end{array}$ \\
\hline 10 & 35.483 & $\begin{array}{c}\text { Upper and lower arm torsion in the } \mathrm{X} \\
\text { direction }\end{array}$ \\
\hline
\end{tabular}

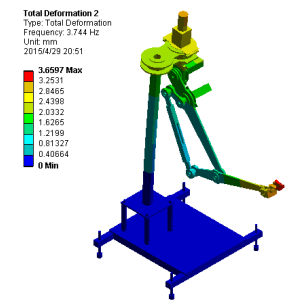

The 2nd mode

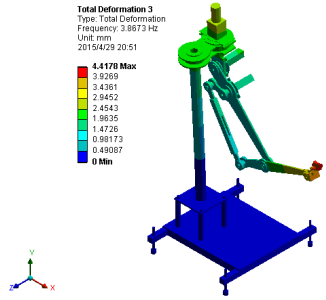

The 3rd mode

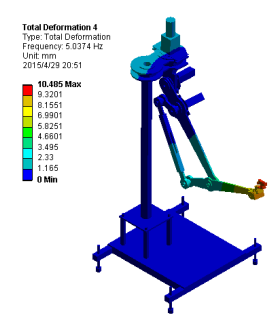

The 4th mode

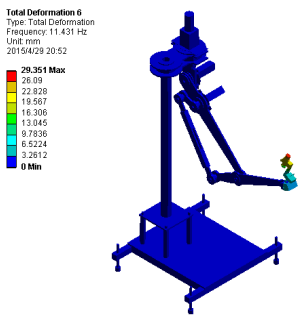

The 6 th mode

The 8th mode

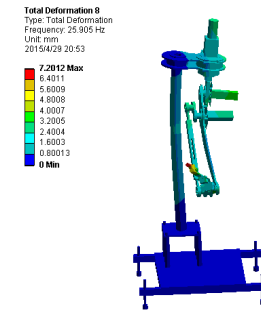

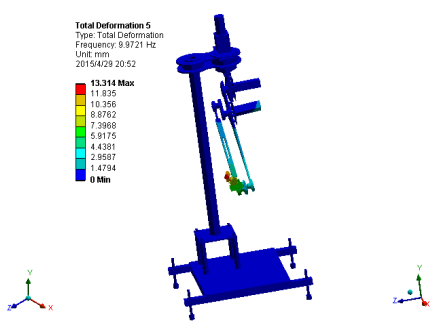

The 5 th mode

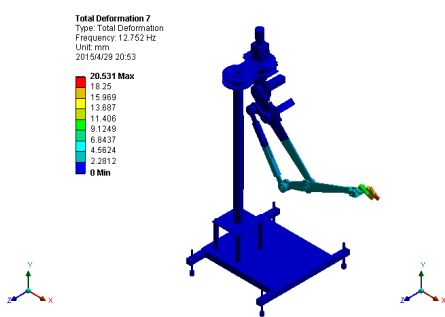

The 7 th mode

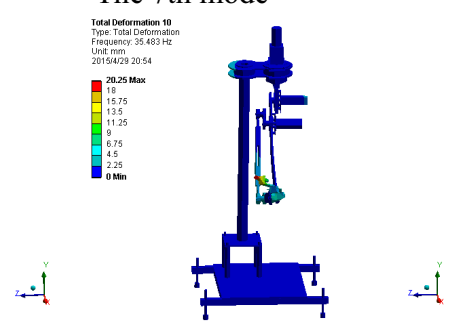

The 10th mode
Figure 3. Parts of the modal shapes.

In harmonic response analysis,the constraint is as same as modal analysis and the frequency range is set to $0-34 \mathrm{~Hz}$.Therefore, the result of harmonic response analysis is shown in Fig. 4:

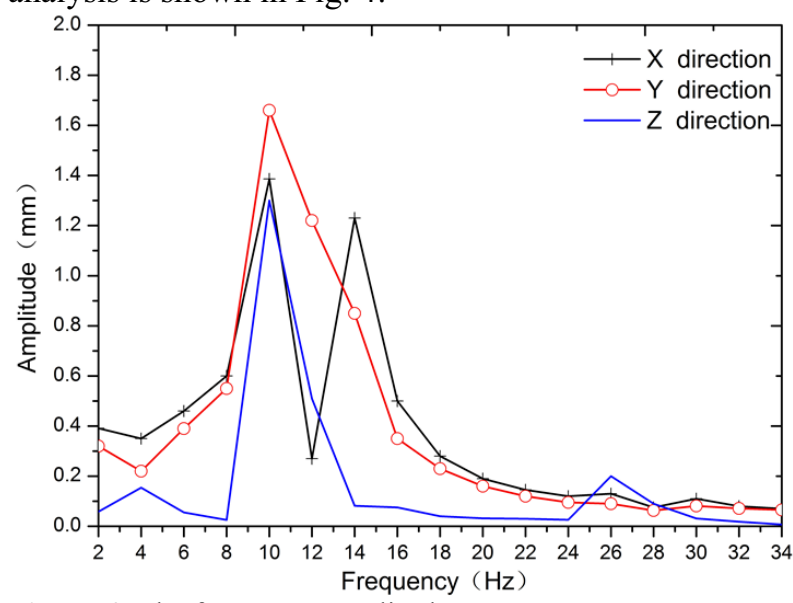

Figure 4. The frequency amplitude response curve.

Fig. 4 shows that the maximum amplitude is generated in $10 \mathrm{~Hz}$ in $\mathrm{X}, \mathrm{Y}, \mathrm{Z}$ directions and the corresponding value is $1.3861 \mathrm{~mm}, 1.6567 \mathrm{~mm}$ and $1.3056 \mathrm{~mm}$. Moreover, the second peak appears in $14 \mathrm{~Hz}$ in $\mathrm{X}$ direction.However, all the peak frequencies are too low and the amplitudes are too large, thus it will affect the manipulator stability and generate an additional dynamic load. Besides, the maximum amplitude frequency is close to the frequency of fifth and sixth order modal thus it will cause the resonance of themanipulator. Thus the structure of manipulator needs redesigned to raise the resonant frequency and stability. 


\section{Structure optimization}

A structure improvement method is proposed in this section.According to the previous analysis, the deformation of rotating support is the main factor which lead to poor dynamic performance of the manipulator. we increase the thickness of rotating support from $2 \mathrm{~mm}$ to 4 $\mathrm{mm}$ and add two ribs to achieve a more stable performance.

Reconstructing and calculating the model, the results of modified and non-modified model are shown in Table 3 and the harmonic response analysis result is shown in Fig. 5.

Table 3. The natural frequency and maximum deformation before and after optimization.

\begin{tabular}{|c|c|c|c|c|}
\hline \multirow[b]{2}{*}{ NO. } & \multicolumn{2}{|c|}{ Non-modified Model } & \multicolumn{2}{|c|}{ Modified Model } \\
\hline & $\begin{array}{c}\text { Frequency } \\
(\mathrm{Hz})\end{array}$ & $\begin{array}{c}\text { Maximum } \\
\text { deformation } \\
(\mathrm{mm})\end{array}$ & $\begin{array}{l}\text { Frequency } \\
(\mathrm{Hz})\end{array}$ & $\begin{array}{c}\text { Maximum } \\
\text { deformation } \\
(\mathrm{mm})\end{array}$ \\
\hline 1 & 3.014 & 3.6597 & 3.927 & 17.589 \\
\hline 2 & 3.744 & 4.4178 & 4.6008 & 5.2506 \\
\hline 3 & 3.8673 & 10.485 & 5.8411 & 5.0431 \\
\hline 4 & 5.0374 & 13.314 & 6.386 & 16.7 \\
\hline 5 & 9.9721 & 29.351 & 10.115 & 13.573 \\
\hline 6 & 11.431 & 20.531 & 14.484 & 22.415 \\
\hline 7 & 12.752 & 7.2012 & 31.683 & 15.694 \\
\hline 8 & 25.905 & 10.494 & 35.672 & 13.45 \\
\hline 9 & 29.917 & 20.25 & 39.743 & 13.603 \\
\hline 10 & 35.483 & 10.68 & 47.524 & 5.5207 \\
\hline
\end{tabular}

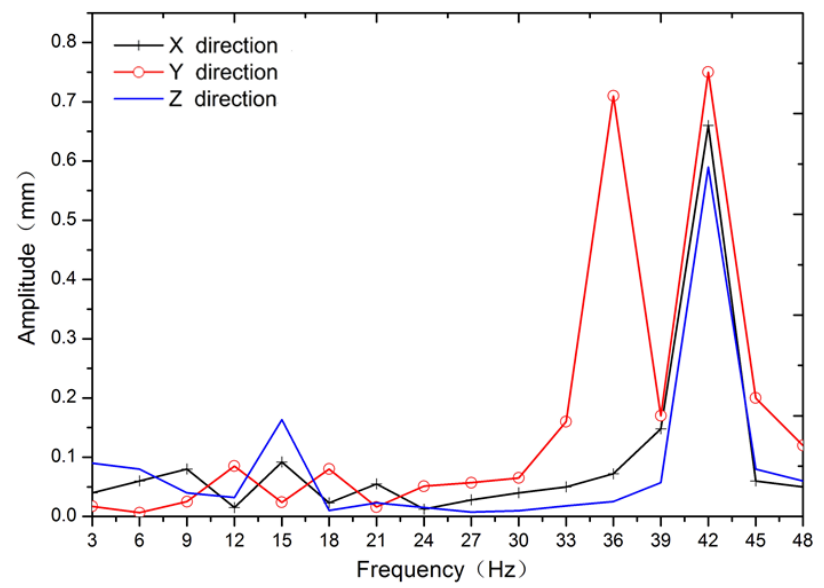

Figure 5. The optimized frequency amplitude response curve.

From Table 3, we can see that the vibration trend is similar to non-modified model, but the natural frequency is raised in different degrees. In particular, the maximum deformation of first order increased $13.485 \mathrm{~mm}$, the fifth order decreased $13.657 \mathrm{~mm}$, the maximum deformation descend form $29.351 \mathrm{~mm}$ to $22.415 \mathrm{mml}$, and the maximum natural frequency is raised to $54 \mathrm{~Hz}$ in modified mode. From Fig. 5, compared with Fig. 3, the maximum amplitude response frequencies ascend from $10 \mathrm{~Hz}$ to $42 \mathrm{~Hz}$ in harmonic response analysis. Furthermore, the second peak frequency is presented to $36 \mathrm{~Hz}$ in $\mathrm{Y}$ direction. The maximum amplitude reduce $0.7255 \mathrm{~mm}$ (from $1.3861 \mathrm{~mm}$ to $0.6606 \mathrm{~mm}$ ) in $\mathrm{X}$ direction, reduce $0.8991 \mathrm{~mm}$ (from $1.6567 \mathrm{~mm}$ to $0.7567 \mathrm{~mm}$ ) in $Y$ direction and reduce $0.71 \mathrm{~mm}$ (from $1.3056 \mathrm{~mm}$ to $0.5956 \mathrm{~mm}$ ) in $\mathrm{Z}$ direction. Through the preceding analysis, the natural frequencies and resonance frequencies are advanced meanwhile the tendency of maximum frequency amplitude is opposite.

The improved-structure based manipulator is manufactured to further verify the dynamic characteristic and the physical picture is shown in Fig. 6. Subsequently, the dynamic performance experiments will be carried out later.

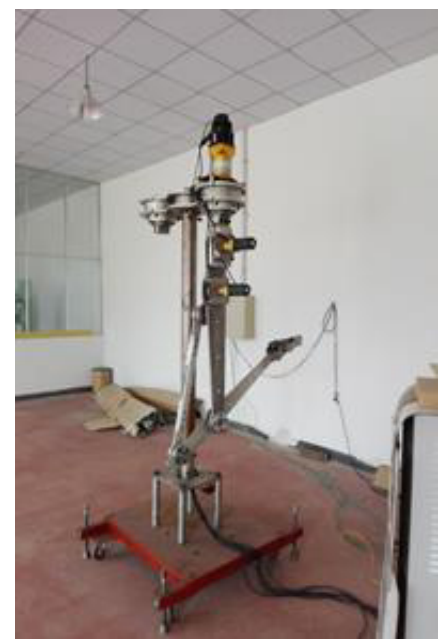

Figure 6. The physical picture of manipulator.

\section{Conclusion}

This article carried on the finite element analysis of a new type of glaze spraying manipulator and improved its structure to achieve a better dynamic characteristics. The calculation results shows that the rotary support has great influence on the deformation of the manipulator. Then an improved scheme is proposed to increase the thickness of rotation support and add ribs in both sides. The natural frequency of the modified structure is grown by $33.9 \%$. Moreover, the maximum deformation of the manipulator was reduced by $52.3 \%, 54.3 \%, 54.4 \%$ in three directions. The dynamic performance of the modified structure is better than non-modified. In addition, the study could lay a theoretical foundation for kinematics, dynamics and deviation analysis, etc.

\section{Acknowledgment}

This work is supported by the National Natural Science Foundation of China ((51165011), the Natural Science Foundation of Jiangxi Province (2010GZC0090), Science 
and Technology Support Program of Jiangxi Province (20122BBE500039) and Technology Landed Plan of Jiangxi Province for Institutions of higher learning.

\section{References}

1. Wang Feng-chao, Wang Li-ping, Liang Xin-cheng, Zhao Jin-shan, Qiu Yun-jie. Research Review of the Intelligent Spraying Robots. The sixth youth science and technology forum of china aviation academy, pp. 675-679, (2014)

2. Wang Tian-miao, Tao Yong, Research Status and Industrialization Development Strategy of Chinese Industrial Robot. Journal of Mechanical Engineering, 9, pp. 1-13, (2014)

3. Zhu Lei-lei, Chen Jun. A Review of Wheeled Mobile Robot. MACHINETOOL \& HYDRAULICS, 242247, (2009).

4. Song Shao-yun, Yin Fang, Sain Vaint Principle of Meshing in Finite Element Method and its Application. Mechanical Design and Manufacturing, 8, pp. 63-65, (2012)

5. Li Da-lei, Ding Tian-tao, Cheng Jian-min, LiNing.Motion analysis for space swinging institutions based on SolidWorks Motion. Manufacturing Automation, 11, pp. 70-71, (2011)

6. Wang Ze-peng, Hu Ren-xi, Kang Shi-ting, Finite element analysis from the entry to the master based on ANSYS Workbench14.5. Mechanical Industry Press, pp. 195-220, (2014)

7. Dong Xu, Li Zhi-jie, Xu Jin-ming, Six degrees freedom industrial robot dynamic characteristics analysis based on ANSYS Workbench. Precision Manufacturing and Automation, 3,pp. 10-13, (2014)

8. Liu Tao, Wang Wei-wu, Lu Fei, Yuan Ren-wu, The model and harmonic response analysis of trunk telescopic boom by Workbench. Manufacturing Automation, 2,pp. 80-82, (2015)

9. Tokhi M O, Mohamed Z, Modeling of a flexible robot manipulator using finite methods: a symbolic approach.Journal of Low Frequency Noise Vibration and Active Control, 18(2), pp. 63-76, (1999).

10. Wang Shu-fen, Zhao Xu-yang, Li Yu-guang, Dynamic Characteristics Analysis of an Automotive Seat Frame. Mechanical Design and Manufacturing, 6, pp. 145-147, (2015)

11. Ji Wen-mei, Fang Tong, Chen Qi-song, Mechanical Vibration. Science Press, 6, 1985. 